\title{
Endothelial Dysfunction Expressed as Endothelial Microparticles in Patients With End-Stage Heart Failure
}

\author{
P. IVAK ${ }^{1,4}$, J. PITHA $^{2}$, P. WOHLFAHRT ${ }^{2,5}$, I. KRALOVA LESNA ${ }^{2}$, P. STAVEK ${ }^{2}$, \\ Z. DORAZILOVA ${ }^{3}$, J. STEPANKOVA ${ }^{3}$, J. MALY ${ }^{1}$, M. POKORNY ${ }^{1}$, I. NETUKA ${ }^{1}$
}

${ }^{1}$ Department of Cardiac Surgery, Institute for Clinical and Experimental Medicine, Prague, Czech Republic, ${ }^{2}$ Laboratory for Atherosclerosis Research, Institute for Clinical and Experimental Medicine, Prague, Czech Republic, ${ }^{3}$ Department of Cardiology, Institute for Clinical and Experimental Medicine, Prague, Czech Republic, ${ }^{4}$ Third Faculty of Medicine, Charles University, Prague, Czech Republic, ${ }^{5}$ International Clinical Research Center, St. Anne's University Hospital, Brno, Czech Republic

Received July 9, 2014

Accepted July 22, 2014

\section{Summary}

Left ventricular assist devices (LVAD), currently used in treatment of terminal heart failure, are working on principle of rotary pump, which generates continuous blood flow. Non-pulsatile flow is supposed to expose endothelial cells to high stress and potential damage. Therefore, we investigated longitudinal changes in concentration of circulating endothelial microparticles (EMP) as a possible marker of endothelial damage before and after implantation of LVAD. Study population comprised 30 patients with end-stage heart failure indicated for implantation of the Heart Mate II LVAD. Concentrations of microparticles were measured as nanomoles per liter relative to phosphatidylserine before and 3 months after implantation. At 3 months after implantation we observed significant decrease in concentration of EMP [5.89 (95\% CI 4.31-8.03) vs. 3.69 (95\% CI 2.70-5.03), $\mathrm{p}=0.03$ ] in the whole group; there was no difference observed between patients with ischemic etiology of heart failure $(n=18)$ and with heart failure of non-ischemic etiology $(n=12)$. In addition, heart failure etiology had no effect on the rate of EMP concentration decrease with time. These results indicate possibility that LVAD do not cause vascular damage 3 months after implantation. Whether these results suggest improvement of vascular wall function and of endothelium is to be proved in long-term studies.

\section{Key words}

Ventricular assist device • Non-pulsatile flow • Circulating endothelial microparticles

\section{Corresponding author}

J. Pitha, Institute for Clinical and Experimental Medicine, Vídeňská 1958/9, 14021 Prague, Czech Republic. E-mail japi@ikem.cz

\section{Introduction}

Use of continuous left-ventricular assist devices (LVAD) for partial or full support of failing heart have become an important and, at this time, also leading therapeutic option for patients with end-stage heart failure of different etiologies along with heart transplantation (Kirklin et al. 2014).

Currently, LVAD are mostly used as a bridge to heart transplant, but the lack of donor organs and also design advancements and increasing reliability of LVAD are widening possibilities of long-term use of these pumps. In the past few years application of mechanical circulatory support continues to rise as permanent therapy/destination therapy. Of interest, in the United States, in 2012 more than $40 \%$ of implants have been designated to destination therapy (Kirklin et al. 2014).

Eligibility of long-term use of LVAD was mainly influenced by design advancements. Firstgeneration pulsatile LVAD had higher complication rate than the latest generation of ventricular assist devices working on the principle of rotary pump with continuousflow (Pagani et al. 2009, Slaughter et al. 2009). 
Generally it is assumed that the presence of nonphysiological continuous blood flow leads to higher stress of endothelial cells, and rises a concern of proatherogenic and prothrombotic changes in endothelium. Surprisingly, this flow pattern of significantly diminished pulsatility is well tolerated in short- and mid-term (Rogers et al. 2010).

Studying long-term use of LVAD offers genuine opportunity of more complex understanding of vascular changes in patients with LVAD and revelation of impact of continuous blood flow on endothelial function. Vascular endothelium plays key role in arterial wall integrity and blood flow regulation (Cines et al. 1998) and recent studies showed that damage of endothelium cells, their activation and/or apoptosis leads to release of newly detectable biomarkers related to endothelial injury - a complex submicron membrane-shed vesicles called endothelial microparticles (EMP) (Schiro et al. 2014).

Microparticles are anuclear fragments of cellular membrane shed from stressed or damaged cells, with a diameter of 0.1 to $1.0 \mu \mathrm{m}$. They contain surface proteins and cytoplasmic material of their parental cells (Burger et al. 2012).

As possible end products of apoptosis of endothelial cells, circulating microparticles can act as a strong disregulators of endothelial function (DignatGeorge et al. 2011). The production of microparticles is believed to be a part of normal cell function but elevation of EMP in coronary artery disease (Bernal-Mizrachi et al. 2004, Singh et al. 2012), stroke (Williams et al. 2007) and in carotid artery disease (Schiro et al. 2014), was well described in several studies and therefore microparticles may be associated with increased risk of major cardiovascular complications (Bernal-Mizrachi et al. 2004).

All these studies were performed in patients with physiological pulsatile flow, and only sparse data are available regarding the role of new potential prognostic cardiovascular risk factor - circulating EMP in patients with end-stage heart failure with continuous-flow LVAD. Almost no data are available describing effect of these devices on EMP in short and long-term perspective. Therefore, the aim of our study was to assess the effect of the mechanical circulatory support on the concentration of circulating EMP after 3 months. In addition, we analyzed whether this effect is different according to etiology of heart failure leading to implantation of LVAD.

\section{Methods}

All the patients included in the study underwent LVAD implantation due to end-stage heart failure and received axial continuous-flow device - HeartMate II (Thoratec Corp., Pleasanton, California). LVAD was implanted via sternotomy in standard fashion as a bridge to heart transplant in all patients.

Heparin bridge has been implemented in all procedures until target anticoagulation with warfarin has been reached. After implantation, the aim of anticoagulation therapy was to reach international normalized ratio of $1.8-2.2$; in patients with trombophilias it was 2.5-3.

Blood samples were collected from peripheral vein during $24-48 \mathrm{~h}$ before and 3 months after implantation. Circulating EMP were measured in an audited lipid laboratory under continuous external quality control of CDC Atlanta, USA. The concentration of EMP was determined by ELISA Zymutest MP activity test (Hyphen Biomed, France) according to the methodology established previously (Slavik et al. 2010) and expressed as nanomoles per liter relative to phosphatidylserine (nM PS). The microparticles were measured in duplicate and the mean of two measurements was used for further analyses.

Prior to procedure, all patients with ischemic heart disease as a cause of heart failure (IHD) were treated with acetylsalicylic acid and statins in contrast to patients with non-ischemic etiology of heart failure (non-IHD). Of note, acetylsalicylic acid has not been administered as a part of antithrombotic regimen.

Institutional ethics committee approval has been obtained prior to the study initiation and all participants provided their signed informed consent.

Data are expressed as mean $\pm \mathrm{SD}$, median (interquartile range-IQR), estimated marginal mean ( $95 \%$ confidence interval) or number (percentage). Differences between IHD and non-IHD group were analyzed using unpaired t-test in the case of continuous variables and Fischer exact test in the case of categorical variables. In graph estimated marginal mean and standard error of the mean (SEM) is plotted. Longitudinal changes in EMP number were analyzed using generalized linear mixed-effect regression model. In this model intercept was treated as a random factor, while time, heart failure etiology and the interaction term between time and etiology, age and gender were treated as fixed factors. Because EMP concentration was right-skewed, we used 
gamma regression (Fitzmaurice et al. 2008). Calculations were done using SPSS 21 (IBM Corporation, NY, USA) and STATA. A two-sided p-value $<0.05$ was considered statistically significant.

\section{Results}

A total of 30 patients, 25 males and 5 females were included into the 3 month prospective study. Mean age of participants was $54.16 \pm 10.03$ years. Eighteen patients were diagnosed with IHD and 12 with non-IHD as a cause of heart failure. Their baseline data are listed in Table 1. We did not find any significant difference between both groups in age, representation of men/women or brain natriuretic factor (BNP) before implantation. The reason of non-significant difference between men and women was caused by a small number of patients in investigated group.

Table 1. Baseline values of selected characteristics of patients treated by left ventricular assist device.

\begin{tabular}{llll}
\hline & $\begin{array}{c}\text { Ischemic } \\
\text { etiology of } \\
\text { heart } \\
\text { failure }\end{array}$ & $\begin{array}{c}\text { Non- } \\
\text { ischemic } \\
\text { etiology of } \\
\text { heart failure }\end{array}$ & p-value \\
\hline$N$ & 18 & 12 & \\
Age (years) & $54.7 \pm 7.99$ & $53.33 \pm 13.20$ & 0.36 \\
$\begin{array}{l}\text { Men/women }(n) \\
\text { Current }\end{array}$ & $17 / 1$ & $8 / 4$ & 0.128 \\
Smokers $(n)$ & 0 & 0 & 1.0 \\
BNP before & $1411 \pm 1422$ & $1473 \pm 867$ & 0.99 \\
implantation of & $(\mathrm{n}=15)$ & $(\mathrm{n}=11)$ & \\
LVAD (ng/l) & & & \\
\hline
\end{tabular}

Results are expressed as mean \pm SD if not stated differently. LVAD - left ventricular assist device; BNP - Brain Natriuretic Peptide.

In the whole group, we observed a significant decrease of circulating EMP before the implantation of LVAD and three months after the procedure [5.89 (95\% CI $4.31-8.03$ ) and 3.69 (95\% CI 2.70-5.03), $\mathrm{p}=0.03$ ] (Fig. 1).

Subsequently we analyzed patients with IHD and non-IHD separately, using generalized linear mixedeffect regression model. Prior to implantation, concentrations of circulating EMP in patients with IHD were not significantly different from patients with non-ischemic etiology of heart failure [5.33 (95\% CI 3.60-7.89) and 6.51 (95\% CI 4.02-10.53), $\mathrm{p}=0.53]$. In addition, using this model, heart failure etiology had no robust effect on the rate of decrease of EMP concentration after LVAD implantation $(p=0.75)$. Furthermore, we did not observe any effect of age $(p=0.72)$ or gender $(p=0.90)$ on the rate of decrease of EMP concentration.

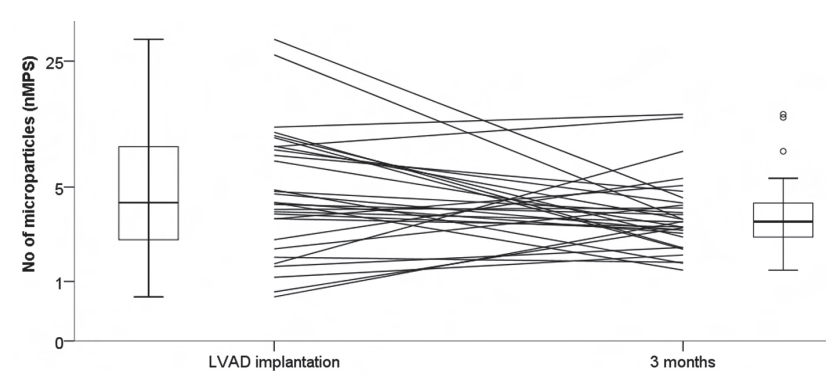

Fig. 1. Concentration of circulating endothelial microparticles before and after implantation of left ventricular assist device (LVAD).

\section{Discussion}

In our study we demonstrated that implantation of LVAD led to significant decrease of EMP during 3 months. Additional finding was that this decrease was not different in patients with IHD and non-IHD as a cause of heart failure. Recent study expands our previous pilot study conducted in 8 male patients (Pitha et al. 2012), where no significant effect of LVAD on concentration of circulating EMP was described, probably due to low number of participants.

To our knowledge only two other studies were focused on EMP during LVAD therapy. In recent study EMP were correlated with clinical complications in 20 patients with LVAD, and significant association between microparticles levels and subsequent clinical events was observed, levels of microparticles were significantly higher in patients who developed an adverse event than in patients with no events (Nascimbene et al. 2014). In another study, levels of microparticles were significantly increased in patients with LVAD compared to healthy controls (Diehl et al. 2010).

Miniaturized, both axial and centrifugal, mechanical ventricular assist devices have demonstrated in last decade undisputable benefit in treatment of patients with end-stage heart failure. Nevertheless, an impact of generated continuous blood flow pattern on vasculature and endothelial cells is not yet clear. It is 
generally assumed, that non-pulsatile flow could exert negative impact on vascular wall and endothelium and may damage endothelial cell membrane and as a result leads to release of endothelial microparticles. Measurement of concentrations of circulating EMP may therefore help to predict endothelial function and may serve as an important biomarker.

Our longitudinal study demonstrates statistically significant decrease in concentration of EMP in patients with end-stage heart failure three months after implantation of continuous LVAD. This finding may suggest improvement of endothelial function of patients on LVAD. Another potential explanation for significant drop of EMP concentration is an improvement of organ perfusion and microcirculation by restoration of adequate systemic output leading to improved status of vasculature in general.

Intensive research of EMP and their function in several cardiovascular pathophysiological processes and also their potential role as biomarkers was conducted in recent years. Despite this fact more analyses are required to establish precise and standardized methods for clinical use of parameters of these EMP and to determine whether their function could be modified to improve prognosis of our patients.

Certain limitation of our study is possible heterogeneity of EMP and still discussed doubts regarding their origin. Therefore, it is still not clear if
EMP really reflect only endothelial damage; however, their detrimental effect was already demonstrated in several studies (Singh et al. 2012, Schiro et al. 2014). Therefore, results of this study indicate that use of continuous flow LVAD does not exhibit detrimental effect to the endothelium in a short term. Nevertheless, additional long-term observations of the EMP dynamics are needed to clarify a chronic effect on microvasculature and endothelial damage. Moreover, correlations with clinical parameters and outcomes are desirable in order to elucidate potential predictive role of EMP as a biomarker of device related adverse events.

In conclusion, in a short term, LVAD exerted rather favorable effect on the vasculature, defined as decreasing number of circulating endothelial microparticles. If this effect is sustained for longer periods must be confirmed in longer longitudinal studies. Nevertheless, based on our recent results this laboratory method might compensate for some technical problems encountered in examination of the status of the vasculature in patients with LVAD.

\section{Conflict of Interest}

There is no conflict of interest.

\section{Acknowledgements}

This study was funded by a grant of Ministry of Health of Czech Republic, IGA MZ NT/14019-3/2013.

\section{References}

BERNAL-MIZRACHI L, JY W, FIERRO C, MACDONOUGH R, VELASQUEZ HA, PUROW J, JIMENEZ JJ, HORSTMAN LL, FERREIRA A, DE MARCHENA E, AHN YS: Endothelial microparticles correlate with high-risk angiographic lesions in acute coronary syndromes. Int J Cardiol 97: 439-446, 2004.

BULUT D, BECKER V, MÜGGE A: Acetylsalicylate reduces endothelial and platelet-derived microparticles in patients with coronary artery disease. Can J Physiol Pharmacol 89: 239-244, 2011.

BURGER D, TOUYZ RM: Cellular biomarkers of endothelial health: microparticles, endothelial progenitor cells and circulating endothelial cells. J Am Soc Hypertens 6: 85-99, 2012.

CINES DB, POLLAK ES, BUCK CA, LOSCALZO J, ZIMMERMAN GA, MCEVER RP, POBER JS, WICK TM, KONKLE BA, SCHWARTZ BS, BARNATHAN ES, MCCRAE EKR, HUG BA, SCHMIDT AM, STERN DM: Endothelial cells in physiology and in the pathophysiology of vascular disorders. Blood 91: 3527-3561, 1998.

DIEHL P, ALEKER M, HELBING T, SOSSONG V, BEYERSDORF F, OLSCHEWSKI M, BODE C, MOSER M: Enhanced microparticles in ventricular assist device patients predict platelet leukocyte and endothelial cell activation. Interact Cardiovasc Thorac Surg 11: 133-137, 2010.

DIGNAT-GEORGE F, BOULANGER CM: The many faces of endothelial microparticles. Aterioscler Thromb Vasc Biol 31: 27-33, 2011.

FITZMAURICE GM, RAVICHANDRAN C: A primer in longitudinal data analysis. Circulation 118: 2005-2010, 2008. 
KIRKLIN JK, NAFTEL DC, PAGANI FD, KORMOS RL, STEVENSON LW, BLUME ED, MILLER MA, TIMOTHY BALDWIN J, YOUNG JB: Sixth INTERMACS annual report: A 10,000-patient database. J Heart Lung Transplant 33: 555-564, 2014.

MOBARREZ F, EGBERG N, ANTOVIC J, BRÖIJERSEN A, JÖRNESKOG G, WALLÉN H: Release of endothelial microparticles in vivo during atorvastatin treatment; a randomized double-blind placebo-controlled study. Thromb Res 129: 95-97, 2012.

NASCIMBENE A, HERNANDEZ R, GEOGE JK, PARKER A, BERGERON AL, PRADHAN S, VIJAYAN KV, CIVITELLO A, SIMPSON L, NAWROT M, LEE VV, MALLIDI HR, DELGADO RM, DONG JF, FRAZIER OH: Association between cell-derived microparticles and adverse events in patients with nonpulsatile left ventricular assist devices. J Heart Lung Transplant 33: 470-477, 2014.

PAGANI FD, MILLER LW, RUSSEL SD, AARONSON KD, JOHN R, BOYLE AJ, CONTE JV, BOGAEV RC, MACGILLIVRAY TE, NAKA Y, MANCINI D, MASSEY HT, CHEN L, KLODELL CT, ARANDA JM, MOAZAMI N, EWALD GA, FARRAR DJ, FAZIER OH: HeartMate II Investigators. Extended mechanical circulatory support with a continuous-flow rotary left ventricular assist device. J Am Coll Cardiol 54: 312-321, 2009.

PITHA J, DORAZILOVA Z, MELENOVSKY V, KRALOVA LESNA I, STAVEK P, STEPANKOVA J, URBAN M, MALY J, NETUKA I: The impact of ventricle assist device on circulating endothelial microparticles - pilot study. Neuroendocrinol Lett 33 (Suppl 2): 68-72, 2012.

ROGERS JG, AARONSON KD, BOYLE AJ, RUSSEL SD, MILANO CA, PAGANI FD, EDWARDS BS, PARK S, JOHN R, CONTE JV, FARRAR DJ, SLAUGHTER MS: HeartMate II Investigators. Continuous flow left ventricular assist device improves functional capacity and quality of life of advanced heart failure patients. J Am Coll Cardiol 55: 1826-1834, 2010.

SCHIRO A, WILKINSON FL, WESTON R, SMYTH JV, SERRACINO-INGLOT F, ALEXANDER MY: Endothelial microparticles as conveyors of information in atherosclerotic disease. Atherosclerosis 234: 295-302, 2014.

SINGH N, VAN CRAEYVELD E, TJWA M, CIARKA A, EMMERECHTS J, DROOGNE W, GORDTS SC, CARLIER V, JACOBS F, FIEUWA S, VANHAECKE J, VAN CLEEMPUT J, DE GEEST B: Circulating apoptotic endothelial cells and apoptotic endothelial microparticles independently predict the presence of cardiac allograft vasculopathy. J Am Coll Cardiol 60: 324-331, 2012.

SLAUGHTER MS, ROGERS JG, MILANO CA, RUSSEL SD, CONTE JV, FELDMAN D, SUN B, TATOOLES AJ, DELGADO RM 3RD, LONG JW, WOZNIAK TC, GHUMMAN W, FARRAR DJ, FRAZIER OH: HeartMate II Investigators. Advanced heart failure treated with continuous-flow left ventricular assist device. N Engl J Med 361: 2241-2251, 2009.

SLAVÍK L: Mikropartikule (in Czech). In vitro diagnostika 16: 19-22, 2010.

WILLIAMS JB, JAUCH EC, LINDSELL CJ, CAMPOS B: Endothelial microparticle levels are similar in acute ischemic stroke and stroke mimics due to activation and not apoptosis/necrosis. Acad Emerg Med 14: 685-690, 2007. 